\title{
The determination of basic fire-fighters rescue operations of key practical importance
}

\author{
Wojciech Jarosz $^{1, *}$, Przemystaw Kowalczyk ${ }^{1}$, Andrzej Marciniak ${ }^{1}$ \\ ${ }^{1}$ The Main School of Fire Service, Faculty of Fire Safety Engineering, 52/54 Slowackiego St., 01-629 \\ Warsaw, Poland
}

\begin{abstract}
According to the act of the State Fire Service fire-fighters are obligated to perform variety of activities in the field of technical, chemical, ecological or other rescue. All these activities require mental and psychical resistance as well as good general health and physical fitness. The aim of the present study was to identify the key rescue activities. Separation of key rescue activities performed by fire-fighters was made in order to evaluate their sensorimotor abilities and to create an unified plan of practical exercises used in training phase. Method of choosing activities that should be included to the "key activities" for practical exercises at the training stage was based not only by their incidence, but also by difficulty level. On the basis of the fire-fighting operations, 39 key rescue operations were selected.
\end{abstract}

\section{Introduction}

Performing difficult and dangerous professions, which undoubtedly include the profession of a fire-fighter, requires many abilities and skills of physical, cognitive, emotional and psychosocial nature. Effective selection to the profession and verification of psychophysical abilities while performing the profession requires the determination of both professional requirements, as well as abilities and skills that allow them to be effectively implemented.

The Act on the State Fire Service (SFS) [1] imposed an obligation on officers to perform a wide range of activities not only in the field of fire-fighting. As statistics from recent years show, most of the actions carried out are so-called local hazards which means performing a number of actions in the field of technical, chemical and ecological, altitude or medical rescue.

All these actions require from rescuers high mental resilience, but also good physical fitness and efficiency, because they are usually associated with considerable physical effort, which is exacerbated by the environment conditions under which fire-fighters work (high and low temperatures, smoke, high humidity). The need for using adequate personal protective equipment, without which it would be impossible and dangerous to carry out many rescue activities, is also of great importance. Despite their continuous improvement and enhancement of ergonomics, these measures still constitute a significant obstacle and additional burden for the user. Heavy clothing and rescue equipment causes metabolic and

${ }^{*}$ Corresponding author: wjarosz@sgsp.edu.pl 
thermoregulatory disorders. Thermal stress leads to many side effects such as a decrease in functional efficiency measured e.g. by speed of walking, excessive strain on the cardiopulmonary system, accelerated muscle fatigue, and thus increases the risk of falls, injuries and changes in walking biomechanics. In addition to the assessment of the time and spatial characteristics of the gait, it is also important to assess the overloading of the skeletal and articular system resulting from excessive load with the heavy protective clothing used.

However, comprehensive studies on the physical fitness of fire-fighters in Poland have not yet been carried out. Instead, an assessment of their physical performance is carried out. The assessment is carried out as a performance test and physical fitness test. Each firefighter under 50 years of age is subject to an annual fitness assessment [2].

A different approach to assessing the physical fitness of fire-fighters is proposed. In the research project entitled "Development of sensory-motor profile and procedures for the National Emergency and Fire System rescuers' physical capacity tests in standardized rescue operations" a number of performance, fitness and exercise tests of fire-fighters were carried out. On this basis, a model of a sensorimotor fire-fighter, a system for testing the physical fitness of fire-fighters and standards for the body performance were developed.

Biomechanical and physiological tests were closely related to physiological evaluation of fire-fighters of different age groups together with the assessment of their psychophysical fitness. The analysis of the dependence of sensorimotor profile evaluation results with the use of laboratory and test methods as well as planned models in polygon tests was used to obtain criteria for optimum methods of assessing fitness and psychophysical performance of the examined persons. Most of the methods used so far in Poland to evaluate fire-fighters allow to determine only some elements of physical fitness, and at the same time they reflect the physical performance of the examined persons only to a minor extent. It should be emphasized that the commonly used method of assessing fire-fighters, consisting in going onto a step at a certain pace and time, was developed 80 years ago, when there were no other ways to determine the physiological response of the body to physical effort.

The main objectives of the project include:

1. Development of a fire-fighter's sensorimotor profile.

2. Development of criteria for assessing psychophysical performance.

3. Development of a new test for assessing the physical fitness of fire-fighters.

In order to obtain them, various research tasks were carried out, e.g:

1. Rescue activities of key practical importance were determined.

2. Methodologies for testing the performance and psychophysical fitness of fire-fighters in laboratory and polygon conditions have been developed.

3. Unified scenarios of exercises for practical training of National Emergency and Fire System fire-fighters have been developed.

4. Studies on testing the performance and psychophysical fitness of fire-fighters polygon conditions have been developed.

Selection of suitable candidates for service and determination of their optimum sensorimotor profile is quite an important issue which may influence not only the later effectiveness, but also the safety of the rescuers themselves. That is why the system of medical examinations and fitness tests for both candidates for service and officers has been used in SFS. However, as it turns out, this system is not fully satisfactory and does not always reflect the actual requirements that will be imposed on fire-fighters during the service. Therefore, an attempt to identify rescue operations of key practical importance, which could help in a better selection of candidates for rescuers, was made. Not only the activities performed by rescuers most often, but also those which, according to the statistics, are performed relatively rarely, but require special psychophysical predispositions, including fitness, strength and endurance, may be of key importance for 
real operations. The identification of these activities was then the basis for the development of scenarios of rescuers' exercises during polygon tests.

As a definition of rescue operations, a provision of the Regulation of the Minister of Internal Affairs and Administration on detailed principles of organisation of the national rescue and fire-fighting system [3] was adopted, where the rescue operation was defined as:

a) basic - activities performed in particular areas of rescue by all rescuers,

b) specialist - activities carried out by appropriately trained rescuers.

\section{Methodology}

The basic criterion for the division of rescue operations carried out by the SFS is the classification of each event into one of three types: fire, other local hazard or false alarm. Another local hazard is an event resulting from the development of civilization and natural laws, which is not a fire or natural disaster, constituting a hazard to life, health, property or the environment, the prevention or removal the effects of which does not require the application of extraordinary measures [1]. Rescue operations during other local hazards are carried out within the framework of:

- Technical rescue.

- Chemical rescue.

- Ecological rescue.

- Medical rescue.

According to this division, in the years 2010-2014, the SFS performed rescue operations during [4]:

- 762911 fires (on average 152582 /year).

- 1359580 other local hazards (on average 271916 per year).

- 100734 events were classified as false alarms, as shown in Fig 1.

This gives an average annual number of interventions at the level of 444645 events.

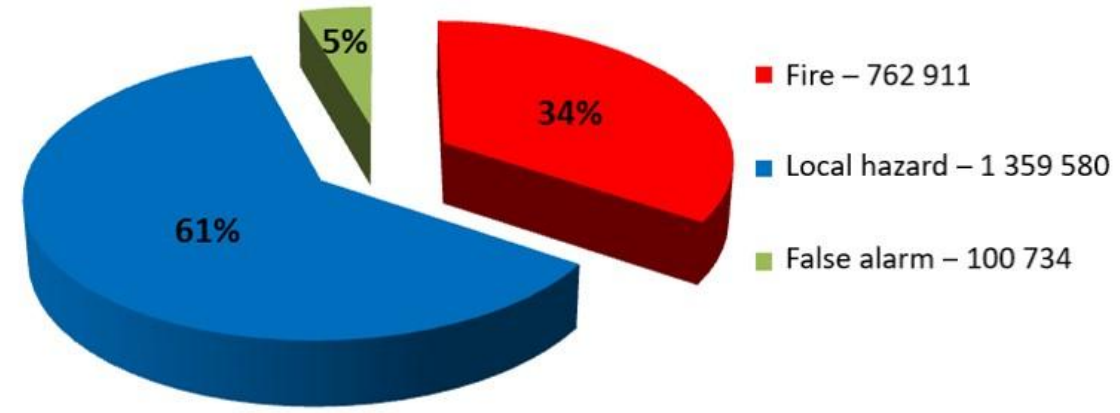

Fig. 1. State Fire Service interventions in the years $2010-2014$.

The majority of the SFS (61\%) are related to technical, chemical and ecological or medical rescue operations. The remaining part is fire-fighting activities related to fires $(34 \%)$ and false alarms $(5 \%)$.

The SFS units keep records of events during which they carried out rescue operations. Documentation of rescue operations includes the preparation of the so-called Event Information. On such basis, the data are entered into the SWD-ST system used by the State Fire Service.

The data contained in the Event Information are quite general, therefore it is necessary to perform a thorough analysis of statistical data and their proper interpretation. The interpretation of the data was based on the knowledge and practical experience of firefighters $[5,6,7]$, which enabled proper analysis of the data obtained from the SWD-ST 
system. The card shown in Figure 2 is the basic data source which the SWD-ST system is based on. The card is filled in by the commander participating directly in the rescue and fire-fighting operation.

The SWD-ST system is a multi-module IT system designed to support work in the District and Municipal Headquarters and in the Provincial Rescue Coordination Headquarters, as well as in the National Rescue Coordination Centre. The application consisting of several interconnected modules constitutes a uniform working environment for all dispatchers of the SFS (Fig. 2.). The system is supplied with data concerning its own area at the district level in the district headquarters of the SFS and in rescue and firefighting units. Some data, especially concerning other districts and provinces, are imported from the province headquarters database. Each piece of information entered is transmitted electronically to a higher-level headquarters or a subordinate unit. This process takes place on an ongoing basis.

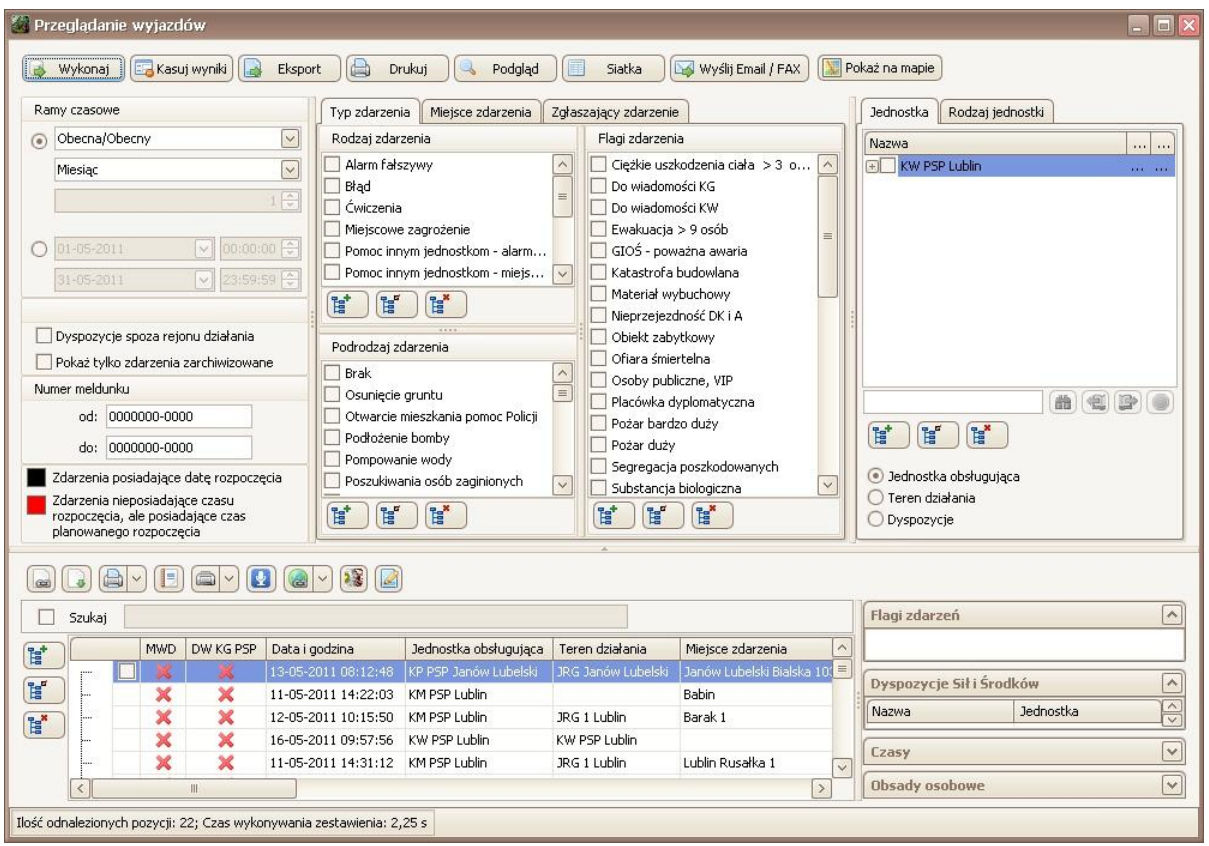

Fig. 2. Browse actions module of the SWD-ST system.

The tests carried out utilised data from SWD-ST system, where information on alarming, dispatching, conducting activities and using various types of technical equipment by fire-fighters during the action is collected and processed. The level of detail of these data assumed in the system, however, does not allow for direct downloading of the necessary information concerning the activities performed by fire-fighters. Hence, the information obtained from the SWD-ST system on the use of technical means during firefighting, technical, chemical and ecological activities was compiled with the fire-fighters' practical knowledge on the types of activities performed during events and failures. In this way data from the years 2010-2014 from all over Poland were analysed. The data on the use of specialist equipment (Fig. 3) during various types of rescue and extinguishing operations by all rescue and extinguishing units of the SFS were examined. As far as technical rescue is concerned, the following data were analysed:

- Use of on-hand demolition equipment.

- The use of hydraulic tools. 
- The use of cutting equipment.

- The use of on-hand ladders.

- Use of other types of equipment.

In the field of chemical and ecological rescue, the data on the following were examined:

- Use of measuring equipment.

- The use of chemical-resistant and gas-tight clothing.

- The use of specialised chemical pumps.

- Use of sealing equipment.

In the field of fire-fighting activities, the data concerning the following aspects were traced:

- Construction of fire-fighting and supply lines.

- Carrying out extinguishing and search activities in the premises.

- Rescue and transport of the injured.

- Smoke extraction in rooms.

- Use of respiratory protective equipment.

- Installation of portable ladders.

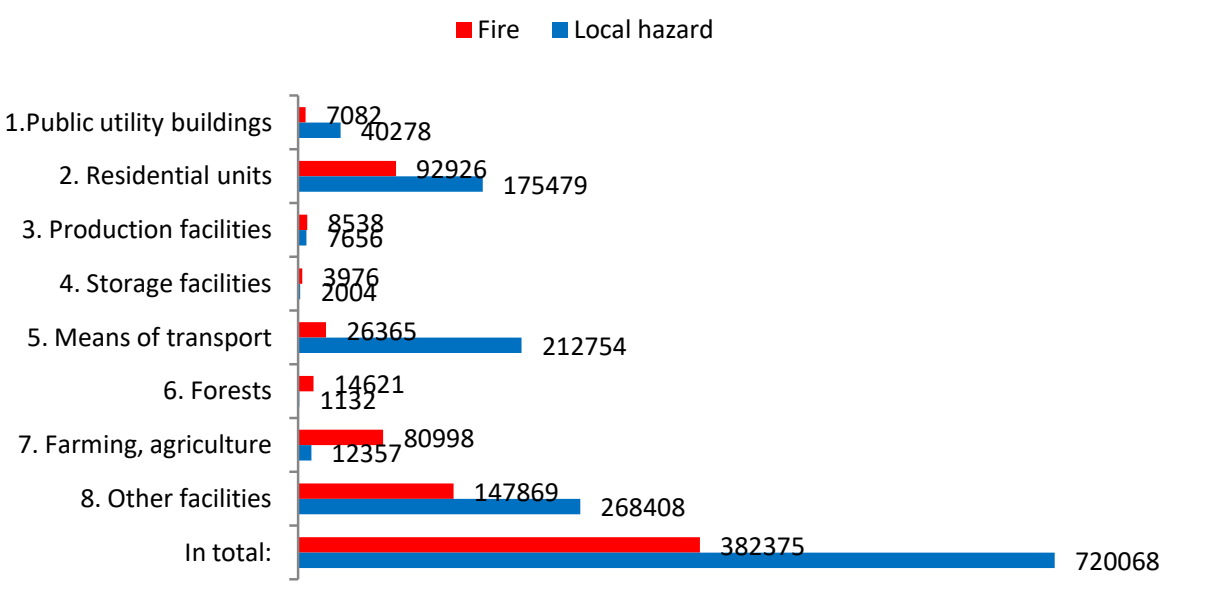

Fig. 3. The use of on-hand demolition equipment in break-down to facilities (examples).

The analysis of the data allowed to identify a set of rescue activities, which were a starting point for determining which of them are of key importance in practice. They were collected on the basis of observations and professional experience of SFS officers. This set consisted of 97 rescue operations concerning all types of operations: 36 fire-fighting actions, 35 chemical and ecological rescue actions and 26 technical rescue actions.

On the basis of this set of activities the key rescue activities, from the practical point of view, were distinguished, depending on the type of activities carried out:

a) in extinguishing activities:

1) Construction of a $60 \mathrm{~m}$ long $\mathrm{W} 75$ hose line.

a) Stairs up to the first floor.

b) Stairs down to the basement.

c) On flat surface.

d) With an access ladder to the second floor.

e) On a flat surface ended with a hydrant rack.

2) Construction of a $60 \mathrm{~m}$ long W52 hose line.

a) Stairs up to the first floor.

b) Stairs down to the basement.

c) On flat surface. 
d) With an access ladder to the second floor.

3) Transport of rescue equipment with a weight of $25 \mathrm{~kg}$ over a distance of $60 \mathrm{~m}$.

a) Stairs up to the first floor.

b) Stairs down to the basement.

c) On flat surface.

d) With an access ladder to the second floor.

4) Work with on-hand demolition equipment weighing $8 \mathrm{~kg}$ for 3 minutes (e.g. forcing doors with a hammer, cutting bars of grids).

5) Operation of the extinguishing station with a capacity of $250 \mathrm{dm} 3 / \mathrm{min}$ and a pressure of 5 bar nozzle, displacement of the extinguishing station over a distance of $20 \mathrm{~m}$ with simultaneous injection of extinguishing current $(10 \mathrm{~m}$ forward and return $10 \mathrm{~m}$ backward - withdrawal).

6) Transport of the injured over a distance of $25 \mathrm{~m}$ (adult weighing $75 \mathrm{~kg}$ ).

a) Stairs up to the first floor.

b) Stairs down to the basement.

c) On flat surface.

d) With an access ladder to the second floor.

e) On the flat surface - the rescuers position "on their knees", under conditions similar to real ones, simulation of an internal fire in the flash-over chamber.

7) Installation of a suction line with the length of $10 \mathrm{~m}$ from a $110 \mathrm{~mm}$ hose.

8) Care over the injured under Qualified First Aid.

\section{b) in chemical and ecological rescue}

1) Securing the place of the event.

2) Construction of 2 main lines (W75) $10 \mathrm{~m}$.

3) Construction of the first extinguishing line ended with a nozzle (W52) $60 \mathrm{~m}$.

4) Construction of the second extinguishing line ended with a curtain (W52) $40 \mathrm{~m}$.

5) Construction of the third extinguishing line to supply the decontamination cabin 20 $\mathrm{m}$.

6) Transfer of rescue equipment over a distance of $10 \mathrm{~m}$.

7) Preparation of rescuers to enter the zone - assistance in putting on protective clothing and apparatus.

8) Carrying out gasometric measurements with delimitation of zone I (dangerous) and marking of the entry and exit zones.

9) Monitoring of the zone boundary while performing the actions.

10) Installation of the decontamination cabin in the exit zone.

11) Rescue and evacuation of injured persons using sheet stretchers (e.g. $60 \mathrm{~kg}$ adult dummy and $80 \mathrm{~kg}$ adult dummy) - transport of injured persons over a distance of $20 \mathrm{~m}$ partly with reduced visibility due to vapours of aggressive substance).

12) Provision of tanks/trays in the leakage location.

13) Sealing - rescuers perform the following activities:

a) Relocation of equipment (plaster/bandages/pins/plugs/sealing wedges).

b) Execution of the seal - often work at a height (on a platform or an access ladder).

14) Collection of spilled substance by means of sorbent.

15) Pumping the contents of the tank into substitute tanks, rescuers perform the following activities:

a) Transfer of the pump and accessories.

b) Installation of the pump.

c) Pumping the medium. 
c) in technical rescue:

1) Protection of the road accident scene,

2) Transfer of rescue equipment over a distance of $20 \mathrm{~m}$;

3) Rescue actions with the use of hydraulic tools (cutting, bursting) for approx. 5 minutes,

4) Extraction and placement of the injured person (approx. $80 \mathrm{~kg}$ dummy) on an orthopaedic board,

5) Transport of the injured person to an ambulance at a distance of approx. 30-50 m,

6) Cardiopulmonary resuscitation for 5 minutes,

7) Neutralisation with sorbent and removal of hazardous materials from the road,

8) Transport of a tripod, ropes, emergency triangle at a distance of about $200 \mathrm{~m}$,

9) Installation of a tripod,

10) Preparation of a lift stand,

11) Descent of one rescuer down,

12) Vertical transport of the injured

13) Transport of wood saw $(8 \mathrm{~kg})$, circular saw $(10 \mathrm{~kg})$ at a distance of $100 \mathrm{~m}$,

14) Cutting of wooden logs (at a height of $1.2 \mathrm{~m}$ for 5 minutes)

15) Cutting of concrete blocks (at height $0.5 \mathrm{~m}$ for 5 minutes).

16) Lifting a car/concrete block with pneumatic cushions.

\section{Conclusions}

The presented key rescue activities are the first attempt to codify a fire-fighter's work by separating the basic activities performed at the scene of a rescue and fire-fighting action. The problem of separating these activities may seem easy by the very observation of the rescuers' work. However, some of the presented key activities are not common (e.g. lifting a concrete block), contrary to the standard, known and obvious (e.g. construction of a hose line). Such a distribution of the frequency of performance of various types of work precludes the use of observation as the only way of analysing and selecting key activities. Therefore, data from the SWD-ST system were used, where information on alarming, dispatching, carrying out activities and the use of various types of technical equipment by fire-fighters during the action is collected and processed. The level of detail of these data assumed in the system, however, does not allow for direct downloading of the necessary information concerning the activities performed by fire-fighters. Hence, the information obtained from the SWD-ST system on the use of technical means during activities of various nature was compared with the knowledge of fire-fighters on the work performed during events and failures. This resource of information given as qualitative data in combination with statistics on the use of rescue and fire-fighting equipment allowed to define a set of key rescue activities. The analysis also takes into account rescue activities performed rarely, but accepted as necessary and key ones from the point of view of the effectiveness of a rescue operation and the necessity of their performance.

The identified key rescue activities were the basis for the preparation of unified scenarios for fire-fighters' exercises. This allowed to carry out polygon tests, which are the grounds for the development of the sensorimotor profile and the test of the physical fitness of fire-fighters.

This work was supported by the Polish National Centre for Research and Development, project DOBBIO6/05/54/2014 


\section{References}

1. Act on the Act of 24 August 1991 on the State Fire Service (Journal of Laws of 1991, No. 88 , item 400 , as amended)

2. Regulation of the Minister of Internal Affairs and Administration of 27 October 2005 on the scope, mode and frequency of periodic preventive medical examinations and periodic assessment of the physical fitness of a State Fire Service fire-fighter (Journal of Laws of 2005, No. 261, item 2191)

3. Regulation of the Minister of Internal Affairs and Administration of 18 February 2011 on detailed rules of organisation of the national rescue and fire-fighting system (Journal of Laws of 2011 No. 46 item 239)

4. SWD-ST - Decision Support System - ST (2015)

5. A. Polańczk, Z. Salamonowicz, E3S Web of Conferences 44, 159 (2018)

6. W. Jarosz, Z. Salamonowicz, M. Majder-Łopatka, R. Matuszkiewicz, A. Dmochowska, Przem. Chem. 93, 5 (2014)

7. Z. Salamonowicz, W. Jarosz, BITP 3, 7 (2012) 